\title{
Ensino Superior e internacionalização: atores e desafios
}

\section{Higher Education and internationalization: actors and challenges}

\section{Enseñanza Superior e internacionalización: actores y desafios}

\author{
Altair Alberto Fávero ${ }^{1}$ \\ Marcio Giusti Trevisol²
}

DOI: http://dx.doi.org/10.20435/serie-estudos.v0i0.1367

\begin{abstract}
Resumo: O artigo discute a internacionalização do Ensino Superior a partir dos atores que atuam no campo das políticas educacionais. O problema investigativo caracteriza-se pela pergunta: quais os sentidos da internacionalização a partir de seus atores? O objetivo é apresentar como a internacionalização é tratada pelos atores que participam da arena de debate das políticas educacionais. A pesquisa é exploratória, com coleta de dados documental. O sentido de internacionalização nos documentos evidencia uma forte tendência de valorização de políticas que garantam o desenvolvimento econômico, em desfavor de políticas de internacionalização que valorizem a diplomacia e as redes solidárias de conhecimento. Para tanto, pode-se inferir que as políticas de internacionalização apresentam várias facetas e intencionalidades oriundas dos atores envolvidos no campo universitário.
\end{abstract}

Palavras-chave: internacionalização; Ensino Superior; atores.

Abstract: The article discusses the internationalization of Higher Education from the actors who work in the field of educational policies. The investigative problem is characterized by the question: what are the meanings of internationalization from its actors? The goal is to present how the internationalization is treated by the actors who participate in the educational policy debate arena. The research is exploratory with documentary data collection. The sense of internationalization present in the documents evidences a strong tendency to value policies that guarantee the economic development, to the detriment of internationalization policies that value diplomacy and knowledge networks. Therefore, it is possible to infer that the internationalization policies present several facets and intentionalities deriving from the actors involved in the university field.

Keywords: internationalization; Higher Education; actors.

\footnotetext{
${ }^{1}$ Universidade de Passo Fundo (UPF), Passo Fundo, Rio Grande do Sul, Brasil.

2 Universidade do Oeste de Santa Catarina (Unoesc), Joaçaba, Santa Catarina, Brasil.
} 
Resumen: El artículo discute la internacionalización de la Enseñanza Superior a partir de los actores que actúan en el campo de las políticas educacionales. El problema investigativo se caracteriza por la cuestión: ¿Cuáles los sentidos de la internacionalización a partir de sus actores? El objetivo es presentar como la internacionalización es tratada por los actores que participan de la arena de debate de las políticas educacionales. La investigación es exploratoria, con colecta de datos documental. El sentido de internacionalización presente en los documentos evidencia una fuerte tendencia de valoración de políticas que garantan el desarrollo económico, en detrimento de políticas de internacionalización que valoran la diplomacia y las redes solidarias de conocimiento. Para tanto se puede inferir que las políticas de internacionalización presentan varias facetas e intencionalidades provenientes de los actores envueltos en el campo universitario.

Palabras clave: internacionalización; Enseñanza Superior; actores.

\section{INTRODUÇÃO}

As políticas de internacionalização têm ocupado um espaço significativo no atual debate da Educação Superior. Para Miranda e Stallivieri (2017), em razão das conexões que tem com o desenvolvimento econômico e com a diplomacia pública, a educação internacional no Brasil precisa receber mais atenção, especialmente no que diz respeito à definição dos interesses nacionais diante do seu processo de internacionalização. As decisões sobre formação de talentos para o futuro do país, uma agenda de cooperação internacional em matéria de transferência de conhecimento, a contribuição nacional aos desafios mundiais e a vinculação das atividades de internacionalização das agendas regionais são questões que o país precisa tratar de forma mais propositiva.

Diante dessa agenda de grande importância conferida à internacionalização, o objetivo da pesquisa é apresentar como os atores que participam da arena de debates na educação definem a internacionalização do Ensino Superior - suas intencionalidades e interesses. Trata-se de uma pesquisa exploratória com coleta de dados documental. Embora tenhamos apresentado uma trajetória da internacionalização por meio de documentos e instituições, a pesquisa procurou descercar os documentos: Internationalization and trade in higher education: opportunities challenges (OECD, 2004); Declaração de Bolonha (1999); Plano Nacional de Educação (2014-2024) (BRASIL, 2014); e Plano Nacional de Pós-Graduação (PNPG) 2011-2020 - Coordenação de Aperfeiçoamento de Pessoal de Nível Superior (Capes) (BRASIL, 2010). O critério de seleção foi a representatividade que esses documentos exercem sobre a definição dos rumos da Educação Superior. A categoria utilizada para análise primária dos documentos foi de Objetivos/Ações 
contidos nos documentos. O método dialético foi utilizado para o tratamento dos dados coletados. Tal método permite decifrar esse complexo campo de interações e permite visualizar para quem e com quais finalidades as políticas educacionais são elaboradas. O método de investigação dialético, de acordo com Kosik (1976, p. 37), é caracterizado por três graus, a saber: "1) minuciosa apropriação da matéria, pelo domínio do material, nele incluído todos os detalhes históricos aplicáveis, disponíveis; 2) análise de cada forma de desenvolvimento do próprio material; 3) investigação da coerência interna, isto é, determinação da unidade das várias formas de desenvolvimento". Os três graus de investigação caracterizam o método de investigação histórico-dialético e o afastam do reducionismo positivista. Por isso, o método dialético é caraterizado pela categoria de totalidade como condição de capturar todas as possibilidades e contradições do fenômeno social estudado.

O artigo é organizado em três partes: na primeira parte, fazemos uma contextualização da internacionalização da Educação Superior na sociedade do conhecimento; na segunda parte, delimitamos um resgate histórico dos principais documentos que procuram modelar um sistema de internacionalização para os Estados e para as instituições de Ensino Superior; na terceira parte, apontamos quais os interesses subjacentes dos programas e documentos que tratam da internacionalização na sociedade do conhecimento e como se traduzem em uma missão universitária.

Portanto, com a pesquisa, é possível apontar que: a) a internacionalização do Ensino Superior é necessária para efetivar a missão das universidades, que se materializam pela extensão, pesquisa e ensino, contudo é fundamental que as políticas que definem a internacionalização sejam refletidas para não favorecerem apenas interesses do mercado global; b) os discursos produzidos por organismos internacionais influenciam as políticas institucionalizadas nos Estados a adotarem metas quantificáveis e mensuráveis sob os critérios de desempenho, eficiência e competividade entre instituições de Ensino Superior e entre os próprios Estados Nacionais; c) os discursos produzidos sobre a internacionalização tendem a favorecer uma aproximação da universidade com a empresa, inclusive, pontuando que as experiências de internacionalização nos cursos de graduação são fundamentais para que os acadêmicos tenham condições de desenvolverem competência para o mercado global. Na pós-graduação, há um movimento crescente de que os programas de internacionalização devem favorecer áreas 
da ciência e tecnologia como primordiais para o desenvolvimento do país. Esse discurso ideológico acarreta valorização de certas áreas tidas como necessárias para o desenvolvimento nacional. É fato que as políticas de internacionalização são importantes para o fortalecimento da missão das universidades, porém é fundamental discutir os caminhos que adotamos, quais os sentidos, quais atores envolvidos e onde pretendemos chegar.

\section{CONTEXTUALIZAÇÃO DA INTERNACIONALIZAÇÃO NA SOCIEDADE CONTEMPORÂNEA}

A tentativa de analisar a questão da internacionalização a partir dos interesses dos atores envolvidos precisa, como pano de fundo, tomar uma definição sobre qual momento histórico se situa a discussão sobre as políticas de internacionalização do Ensino Superior. Notoriamente, a maioria dos pesquisadores da área concorda que a internacionalização é tão antiga quanto a própria universidade. Para Santos e Almeida Filho (2012), o conceito de internacionalização do século XXI reforça uma característica universitária que vem desde a Idade Média. A internacionalização historicamente é uma das características fundamentais das universidades, contudo seus contornos são diferentes na sociedade globalizada que se estrutura, sobretudo a partir das duas últimas décadas do século XX.

No contexto contemporâneo, pesquisadores, filósofos, sociólogos, antropólogos, entre outros, debruçaram-se para compreender as mudanças típicas da sociedade globalizada, marcada profundamente pelo modelo produtivo neoliberal. Entre os pesquisadores, citamos Giddens (1991), com o conceito de alta modernidade; Habermas (2002), com o conceito de Capitalismo Tardio; Bauman (2001), com o conceito de modernidade líquida; e Beck (2011), com o conceito de sociedade de risco. Embora esses pesquisadores e outros tenham formas e compreensões diferentes para entender o fenômeno da sociedade globalizada, todos concordam que esse momento é marcado pela complexidade. Segundo Cenci e Marcon (2016), a complexificação da sociedade se expressa, entre outras características, por um contexto de grandes transformações da dimensão da vida humana, grande e variado desenvolvimento tecnológico, desenvolvimento dos meios de comunicação e das tecnologias digitais em rede, redimensionamento das categorias de espaço e tempo, emergência de novos atores sociais e movimentos, 
trabalho flexível, predomínio do capital global e especulativo, transformação do conhecimento em força produtiva, dentre outras características.

A complexidade da sociedade apontada pelos autores carrega em sua esteira um discurso unificador e hegemônico que se consolida no cotidiano social e estabelece metas e objetivos para os Estados Nacionais e para as instituições, sejam públicas, sejam privadas. O discurso absoluto, de acordo com Cenci e Marcon (2016, p. 113), é do neoliberalismo, que atribui às forças do mercado e da tecnociência os fundamentos organizativos da vida social. Essa perspectiva é apontada por Sader e Gentili (1995), quando da organização do livro Pós- neoliberalismo: as políticas sociais e o Estado democrático em que apresentam teses que comprovam que as políticas neoliberais enfraquecem a soberania dos Estados Nacionais e fragilizam as políticas públicas, sobretudo as ligadas à educação e saúde. Segundo Dardot e Laval (2016, p. 16):

Tudo isso são condições complementares da nova razão do mundo. Devemos entender, por isso, que essa razão é global, nos dois sentidos que pode ter o termo: é "mundial", no sentido de que vale de imediato para o mundo todo; e, ademais, longe de limitar-se à esfera econômica, tende à totalização, isto é, a "fazer o mundo" por seu poder de integração de todas as dimensões da existência humana. Razão do mundo, mas ao mesmo tempo uma razão-mundo.

Para os autores, o alicerce da globalização neoliberal se sustenta em uma racionalidade e, como tal, tende a estruturar não apenas Estados e governos, mas a própria conduta dos cidadãos (governados). A principal característica da racionalidade neoliberal é a concorrência como norma de conduta para os Estados Nacionais, para as empresas e para definição da própria subjetividade do sujeito. Segundo Dardot e Laval (2016, p. 17), "o neoliberalismo pode ser definido como um conjunto de discursos, práticas e dispositivos que determinam um novo modo de governo dos homens segundo o princípio universal da concorrência".

No contexto contemporâneo, é necessário considerar os escritos de Harvey (2016), sobretudo para situar a universidade no contexto da produção flexível. O autor realiza uma explicação sobre as diferenças de uma sociedade organizada a partir do modelo de produção fordista e de uma sociedade organizada a partir do modelo toyotista ou de acumulação flexível. O fordismo pós-guerra mergulhou em um crescimento fenomenal pós-guerra, mas que dependeu de uma série de 
compromissos e reposicionamentos por parte dos principais atores dos processos de desenvolvimento capitalista, especialmente, o Estado.

Para Harvey (2016), o Estado assumiu novos papéis e construiu novos poderes institucionais. O capital corporativo teve de ajustar as velas em certos aspectos para seguir com mais suavidade a trilha da lucratividade. O trabalho organizado teve de assumir novos papéis e ficções relativos ao desempenho nos mercados de trabalho e nos processos de produção. O equilíbrio de poder tenso, mas mesmo assim firme, que prevalecia entre o trabalho organizado, o grande capital corporativo e a Nação-Estado, formando a base de poder da expansão de pós-guerra, não foi alcançado por acaso, mas sim fruto de lutas. Ligado a esse equilíbrio para o sucesso do modelo produtivo fordista, Harvey (2016, p. 125) lembra outra variável: a "derrota dos movimentos operários que surgiram no período pós-guerra". O sucesso do fordismo estava ligado ao papel do Estado, no trabalho organizado, na produção em massa por meio da linha de montagem, do consumo em massa, do enfraquecimento dos movimentos operários, no sucesso do keynesianismo e no tempo linear e rígido da produção. Em outras palavras, o modelo produtivo Fordista/Taylorista organizava a sociedade a partir da definição clara de tempo e espaço.

No entanto, mesmo com aparente sucesso, o fordismo não conseguiu vencer suas próprias contradições, sobretudo entre 1965 e 1973. Para Harvey (2016), essas dificuldades podem ser resumidas em uma única palavra: rigidez. O autor destaca que "havia problemas com a rigidez dos investimentos de capital fixo de larga escala e de longo prazo em sistemas de produção em massa que impediam muita flexibilidade de planejamento e presumiam crescimento estável em mercado de consumo invariante" (HARVEY, 2016, p. 135). A forte rigidez que impedia o aumento da produção de capital era expressa no mercado, na alocação, nos contratos de trabalho, nas políticas protetivas do Estado, nos novos movimentos sociais e operários que imprimiam greves e, por isso, tornavam inviável o progresso.

Nos anos seguintes a 1970, a economia precisava superar o fordismo e garantir outra forma produtiva, mais efetiva e eficaz. Como já mencionamos, as políticas neoliberais passaram a ser implantadas e foram um enfrentamento ao modelo fordista de produção. A nova forma de acumulação de capital passou a ser baseada na flexibilidade. Para Harvey (2016, p. 14), "a acumulação flexível é marcada por um confronto direto com a rigidez do fordismo. Ela se apoia na 
flexibilidade dos processos de trabalho, dos mercados de trabalho, dos produtos e padrões de consumo".

No modelo de acumulação flexível, o conhecimento se torna uma moeda valiosa. Atento a essa condição, para Harvey (2016), o acesso ao conhecimento científico e técnico sempre teve importância na luta pela competividade. O saber se torna uma mercadoria-chave a ser produzida e vendida a quem pagar mais, sob a condição que são elas mesmas cada vez mais organizadas em bases competitivas. As universidades e centros de pesquisa passam a competir. A produção organizada de conhecimento passou por notável expansão nas últimas décadas, ao mesmo tempo que assumiu cada vez mais um cunho comercial. O autor finaliza sua análise exemplificando essa tendência com o crescimento de centros de pesquisa de alta tecnologia, como Vale do Silício, a Rota 128 MIT-Boston e as várias universidades que buscam destaque na formação de prêmios Nobel. Acrescidas ao conhecimento, a tecnologia da informação e a globalização contribuíram para o surgimento de grandes conglomerados comerciais que se tornaram transnacionais e, em muitos casos, comprometeram o Estado Social.

Os apontamentos levantados até aqui nos permitem olhar para uma dinâmica social da sociedade globalizada que se sustenta sobre uma lógica do mercado, amparada por uma racionalidade da concorrência e competividade. Cabe, nesse momento, levantarmos as seguintes questões: como a educação (de forma totalizante) incorpora esse discurso contemporâneo? Mais especificamente, como a internacionalização do Ensino Superior se estrutura e define suas metas e objetos tomando como base esse contexto histórico? Para quem e sob quais interesses e intencionalidades se estruturam as políticas de internacionalização do Ensino Superior?

No contexto do neoliberalismo se estrutura uma economia do conhecimento. Para Silva (2017, p. 115), aumenta o dilema entre a sociedade do conhecimento e a economia do conhecimento. A emergência dessa nova ordem mundial é fundamentada na razão de mundo da competividade e da concorrência, conduzindo para uma nova condição educativa, à medida que as políticas educacionais passam a objetivar o desempenho e o sucesso.

As questões passam a ser pauta de agências e organismos internacionais como o Banco Mundial, a Organização para a Cooperação e o Desenvolvimento Econômico (OCDE) e a Organização das Nações Unidas para a Educação, a Ciência 
e a Cultura (Unesco), que consideram a educação como mola propulsora do desenvolvimento econômico e social. A introdução desses novos atores, sobretudo nas últimas três décadas, tem levado à estruturação de políticas educacionais que asseguram os interesses do capital global.

\section{ATORES E PROGRAMAS DE INTERNACIONALIZAÇÃO}

A questão da internacionalização tem ocupado espaços de discussão em nível mundial, nacional e local. São várias as instituições e organismos nacionais e internacionais que têm apontado a importância da internacionalização para a consolidação da missão universitária. Segundo Knight (2015, p. 16), "A internacionalização é um processo de introdução da dimensão internacional na cultura e na estratégia institucional, nas funções de formação, investigação, e extensão e na projeção da oferta e das capacidades universitárias".

Embora seja difícil a definição e padronização de modelos de internacionalização para as instituições de Ensino Superior, dada a gênese e as particularidades de cada região e das universidades, existe um consenso de que a internacionalização é um dos caminhos promissores para assegurar o espaço universitário na sociedade global. Tomando esse pressuposto, organismos internacionais coordenam e elaboram documentos que tratam dessa perspectiva, o que é visualizado no Quadro 1.

Quadro 1 - Atores, documentos e objetivos

\begin{tabular}{|l|l|}
\hline $\begin{array}{c}\text { Ator, organismos ou documen- } \\
\text { to a partir de 1920 }\end{array}$ & \multicolumn{1}{c|}{ Objetivos/Ações } \\
\hline Internacional Understanding & $\begin{array}{l}\text { Também conhecido como International Education. } \\
\text { Pretendia fortalecer uma mobilidade estudantil } \\
\text { após a Segunda Guerra, para uma convivência pací- } \\
\text { fica entre os povos. }\end{array}$ \\
\hline $\begin{array}{l}1922 \text { - Cria-se o Committee on } \\
\text { Intellectual Cooperation }\end{array}$ & $\begin{array}{l}\text { Objetivo de criar um fundo mundial para pesquisas } \\
\text { científicas e para o financiamento internacional de } \\
\text { pesquisadores. }\end{array}$ \\
\hline $\begin{array}{l}1930-\text { International Institute of } \\
\text { Intellectual Cooperation }\end{array}$ & $\begin{array}{l}\text { Compreensão de que os intercâmbios culturais são } \\
\text { importantes para o desenvolvimento dos jovens, as- } \\
\text { segurando a aprendizagem de um idioma, contato } \\
\text { com outros povos e entendimento entre nações. }\end{array}$ \\
\hline
\end{tabular}




\begin{tabular}{|c|c|}
\hline $\begin{array}{l}\text { Ator, organismos ou documen- } \\
\text { to a partir de } 1920\end{array}$ & Objetivos/Ações \\
\hline $\begin{array}{l}1946 \text { - Comissão Fulbright dos } \\
\text { Estados Unidos }\end{array}$ & $\begin{array}{l}\text { Objetiva o financiamento por parte de ação gover- } \\
\text { namental para envio de estudantes para outros pa- } \\
\text { íses e recrutamento de estudantes e de professores } \\
\text { estrangeiros, desenvolvendo parcerias internacio- } \\
\text { nais mediante acordo de colaboração. }\end{array}$ \\
\hline 1950 - Unesco (Study Abroad) & $\begin{array}{l}\text { Objetiva um programa de internacionalização que } \\
\text { tenha os compromissos de desenvolvimento da ci- } \\
\text { ência e do aluno, mas que, sobretudo, tenha um } \\
\text { compromisso de desenvolver a compreensão e co- } \\
\text { laboração entre as nações. Pela primeira vez, apare- } \\
\text { ce a internacionalização como perspectiva de diplo- } \\
\text { macia entre nações e povos. }\end{array}$ \\
\hline Década de 1980 - Erasmus & $\begin{array}{l}\text { O programa Erasmus busca promover a mobilidade } \\
\text { acadêmica entre os países-membros da Comunida- } \\
\text { de Europeia. }\end{array}$ \\
\hline $\begin{array}{l}\text { Community Action Programme } \\
\text { for Education and Training for } \\
\text { Technology }\end{array}$ & $\begin{array}{l}\text { Objetiva a aproximação da cooperação internacio- } \\
\text { nal entre universidade e a indústria de capacitação } \\
\text { para a tecnologia. }\end{array}$ \\
\hline $\begin{array}{l}\text { The Trans-European Mobility } \\
\text { Scheme for University Studies }\end{array}$ & $\begin{array}{l}\text { Objetiva a expansão da internacionalização do En- } \\
\text { sino Superior com a entrada de países da Europa } \\
\text { Central e do Leste, originalmente Polônia e Hungria. }\end{array}$ \\
\hline Programa Credit Transfer System & $\begin{array}{l}\text { Este programa é uma continuação do programa } \\
\text { Erasmus e objetiva o reconhecimento de estudos } \\
\text { e de transferência de créditos, estimulando mais a } \\
\text { mobilidade estudantil. }\end{array}$ \\
\hline $\begin{array}{l}1998 \text { - Declaração Mundial so- } \\
\text { bre Educação para Todos - Unes- } \\
\text { co }\end{array}$ & $\begin{array}{l}\text { Objetiva apontar os desafios e as metas da Educa- } \\
\text { ção Superior para o século XXI, entre elas, o enten- } \\
\text { dimento de que a internacionalização como coope- } \\
\text { ração é a missão das universidades no século XXI. }\end{array}$ \\
\hline 1999 - Declaração de Bolonha & $\begin{array}{l}\text { Leva como base os aspectos fundamentais de: em- } \\
\text { pregabilidade, mobilidade e competitividade. O ob- } \\
\text { jetivo é promover a internacionalização no Espaço } \\
\text { Europeu, para que se constitua em um campo for- } \\
\text { talecido cientificamente e faça frente às pressões } \\
\text { globais. Assim, fundamentam-se condições claras } \\
\text { para que as instituições de Ensino Superior saiam } \\
\text { das fronteiras europeias e tornem-se atrativas e } \\
\text { competitivas no mercado da educação mundial. }\end{array}$ \\
\hline
\end{tabular}




\begin{tabular}{|l|l|}
\hline $\begin{array}{l}\text { Ator, organismos ou documen- } \\
\text { to a partir de 1920 }\end{array}$ & \multicolumn{1}{c|}{ Objetivos/Ações } \\
\hline $\begin{array}{l}\text { 2009 - Conferência Mundial so- } \\
\text { bre Ensino Superior 2009: As No- } \\
\text { vas Dinâmicas do Ensino Supe- } \\
\text { rior e Pesquisas para a Mudan- } \\
\text { ça e o Desenvolvimento Social } \\
\text { (UNESCO, 2009) }\end{array}$ & $\begin{array}{l}\text { xima a internavés da conferência, avaliar a agen- } \\
\text { aos conceitos de competização da Educação Superior } \\
\text { ideal de cooperação acadêmica perde espaço para } \\
\text { um ideal de ranqueamento. Ainda importante pon- } \\
\text { tuar o documento da Unesco intitulado Educação } \\
\text { Superior: reforma, mudança e internacionalização } \\
\text { (BRASIL, 2003). }\end{array}$ \\
\hline $\begin{array}{l}\text { Organização para a Cooperação } \\
\text { e Desenvolvimento Econômico } \\
\text { (OCDE) }\end{array}$ & $\begin{array}{l}\text { É importante destacar a presença da OCDE, prin- } \\
\text { cipalmente pelo fato de que os relatórios sobre a } \\
\text { educação têm influenciado as políticas públicas em } \\
\text { educação nos países, condição essa que se expressa } \\
\text { nas avaliações dos programas de internacionaliza- } \\
\text { ção da Educação Superior. }\end{array}$ \\
\hline
\end{tabular}

Fonte: Stallivieri (2017).

O quadro apresenta alguns documentos e organizações internacionais que tratam as questões da internacionalização. Em especial, é importante destacar a presença da Unesco, da OCDE e do Tratado de Bolonha, que têm influenciado permanentemente as políticas de internacionalização adotadas pelo Brasil. Segundo Stallivieri (2017, p. 98), a declaração da Unesco de 1998 assume a internacionalização como cooperação internacional e as instituições de Ensino Superior iniciam uma forte corrida em busca de uma inserção nos programas de mobilidade. A qualidade institucional passou a ser medida pela quantidade do número de ações de mobilidade acadêmica em comparação a outras instituições. Essa condição pontuada por Stallivieri (2017), na prática, elevou um sentido de competitividade e uma maneira de assegurar a posição nos rankings de avaliação internacional.

A Organização de Cooperação e de Desenvolvimento Econômico (OCDE) tem orientado discussões em torno da internacionalização do Ensino Superior. $\mathrm{O}$ documento da OECD, Internationalization and trade in higher education: opportunities challenges de 2004, estabeleceu alguns parâmetros para definir as modalidades de atividades desenvolvidas no exterior. Stallivieri (2017, p. 106-11) pontua, a partir da OCDE, algumas modalidades, a saber: semestre no exterior, 
duplo diploma, programas em conjunto, programas de verão, programas de curta duração, programas de línguas estrangeiras, estágio acadêmico, trabalhos voluntários. No mesmo sentido, Gacel-Àvila e Rodriguez-Rodriguez (2018, p. 117) consideram que, no processo de internacionalização, faltam estruturas organizacionais institucionalizadas e profissionalizadas, pois ele carece de planejamento e avaliação e possui uma gestão principalmente reativa. A imposição de formas dadas pelos organismos internacionais impossibilita que as instituições definam e delimitem uma internacionalização compreensiva.

Por outro lado, a Declaração de Bolonha (1999) possui como objetivo construir o Espaço Europeu de Ensino Superior, sendo reconhecidamente um fator imprescindível ao crescimento social e humano, um elemento indispensável à consolidação e às oportunidades que possibilitarão aos seus cidadãos o desenvolvimento de "aptidões necessárias para enfrentar os desafios do novo milênio", aliando "a consciência de partilha dos valores" e a "pertença a um espaço social e cultural comum". De acordo com Almeida, Fávero e Tonieto (2015, p. 237):

Pode-se concluir a partir de tais afirmações que o objeto é contribuir para a construção de uma Europa referência em produção do conhecimento, fato que contribuiria significativamente para o desenvolvimento social e humano, pois dotaria seus cidadãos de condições para enfrentar os desafios postos pelas demandas, principalmente econômicas, da era da globalização e competividade mundial imposta pela inovação tecnológica e abertura de novos mercados.

Os apontamentos dos autores se confirmam com os levantamentos conceituais do processo de Bolonha realizados por Santos e Almeida Filho (2012, p. 67), que evidenciam para: a atratividade e a competividade, para a legalidade e a comparabilidade, promoção da mobilidade e a promoção da dimensão europeia, em conteúdo, orientação e organização.

Os três agentes, ou como denominamos no artigo, a saber, OCDE, Unesco e Declaração de Bolonha (1999), têm pautado as discussões sobre Ensino Superior em nível internacional. No que se refere à internacionalização, o dualismo entre uma perspectiva de cooperação acadêmica e uma perspectiva de competividade aparece duelando nos documentos e objetivos propostos pelos organismos internacionais. 
Quadro 2 - Atores, documentos e políticas de internacionalização no Brasil

\begin{tabular}{|c|c|}
\hline $\begin{array}{l}\text { Ator, organismo ou } \\
\text { documento }\end{array}$ & Objetivos/Ações \\
\hline $\begin{array}{|lll|}\text { Reforma } & \text { Universitária } & \text { de } \\
1968 & & \\
\end{array}$ & $\begin{array}{l}\text { Por meio da CAPES e do Conselho Nacional de } \\
\text { Desenvolvimento Científico e Tecnológico (CNPq), o } \\
\text { Estado brasileiro passou a financiar bolsas de estudo } \\
\text { para mobilidade internacional, ainda vinculada ao } \\
\text { nível de pós-graduação. O objetivo é estabelecer uma } \\
\text { cooperação internacional na área de pesquisa. A } \\
\text { tendência da política de internacionalização brasileira } \\
\text { esteve fortemente ligada à tendência europeia e } \\
\text { americana. }\end{array}$ \\
\hline $\begin{array}{l}\text { Conselho de Reitores das } \\
\text { Universidades Brasileiras de } \\
1988\end{array}$ & $\begin{array}{l}\text { Criado um fórum específico para discutir as questões } \\
\text { de cooperação acadêmica internacional. O Fórum das } \\
\text { Assessorias das Universidades Brasileiras para Assuntos } \\
\text { Internacionais (FAUBAI) passa a ser o interlocutor } \\
\text { privilegiado para a discussão de propostas e de } \\
\text { programas que tratem da inserção do Brasil no cenário } \\
\text { da educação internacional (STALLIVIERI, 2017, p. 96). }\end{array}$ \\
\hline \begin{tabular}{|ll|}
\multicolumn{1}{|c}{ Associação } & Brasileira de \\
Educação & Internacional \\
(Faubai), 1988 &
\end{tabular} & $\begin{array}{l}\text { Objetivo: além de organizar as ações de Cooperação } \\
\text { Internacional (Cl), fomentar a mobilidade estudantil } \\
\text { e inserir o Brasil nos programas já promovidos pelas } \\
\text { agências de intercâmbio acadêmico, a saber: Serviço } \\
\text { Alemão de Intercâmbio Acadêmico (Daad), Campus } \\
\text { France, Comissão Fulbright, British Council, Agência } \\
\text { Espanhola de Cooperação para o Desenvolvimento } \\
\text { (Aecid), entre outros (STALLIVIERI, 2017, p. 96). }\end{array}$ \\
\hline $\begin{array}{l}\text { CAPES - Plano Nacional } \\
\text { de Pós-Graduação (PNPG) } \\
2011-2020\end{array}$ & $\begin{array}{l}\text { Importante documento de políticas educacionais para o } \\
\text { Ensino Superior. No capítulo } 11 \text { - Internacionalização da } \\
\text { pós-graduação e cooperação internacional, apresenta a } \\
\text { relevância da ciência brasileira em nível internacional. } \\
\text { Objetiva apresentar os avanços da internacionalização e } \\
\text { mostrar a presença de empresas brasileiras no cenário } \\
\text { global. }\end{array}$ \\
\hline
\end{tabular}




\begin{tabular}{|l|l|}
\hline \multicolumn{1}{|c|}{$\begin{array}{c}\text { Ator, organismo ou } \\
\text { documento }\end{array}$} & \multicolumn{1}{c|}{ Objetivos/Ações } \\
\hline Plano Nacional de Educação & \multicolumn{1}{|c|}{$\begin{array}{l}\text { Na meta 14, o Plano Nacional de Educação aponta no } \\
\text { item 14.9: "consolidar programas, projetos e ações que } \\
\text { objetivem a internacionalização da pesquisa e da pós- } \\
\text { graduação brasileiras, incentivando a atuação em rede } \\
\text { e o fortalecimento de grupos de pesquisa"; no item } \\
\text { 14.10, "promover o intercâmbio científico e tecnológico, } \\
\text { nacional e internacional, entre as instituições de } \\
\text { ensino, pesquisa e extensão"; no item 14.11, "ampliar o } \\
\text { investimento em pesquisa com foco em desenvolvimento } \\
\text { e estímulo à inovação, bem como incrementara formação } \\
\text { de recursos humanos para a inovação, de modo a buscar } \\
\text { o aumento da competitividade das empresas de base } \\
\text { tecnológica" (BRASIL, 2014, p. 78). O Plano Nacional de } \\
\text { Educação objetiva apontar os caminhos e as direções } \\
\text { das políticas educacionais que devem orientar os Planos } \\
\text { de Desenvolvimento Institucionais (PDI). }\end{array}$} \\
\hline $\begin{array}{l}\text { O programa CsF buscou promover a consolidação, } \\
\text { expansão e internacionalização da ciência e tecnologia, } \\
\text { da inovação e da competitividade brasileira por meio } \\
\text { do intercâmbio e da mobilidade internacional. Criado } \\
\text { durante o governo Dilma Rousseff. O financiamento } \\
\text { (BRASIL, 2011) } \\
\text { estava ligado à Capes, ao CNPq e a empresas parceiras. }\end{array}$ \\
\hline
\end{tabular}

Fonte: Autoria própria.

Além dos programas, documentos e políticas de internacionalização citados no Quadro 2, é importante destacar o documento $A$ internacionalização da Universidade Brasileira: resultado do questionário aplicado pela Capes (2017), no qual se apresenta uma radiografia atual da internacionalização das instituições de Ensino Superior. Para a Capes (2017, p. 44),

A internacionalização das Universidades Brasileiras é um processo necessário para que se permita que a educação superior se torne responsiva aos desafios de uma sociedade globalizada, mas deve ser entendida como um meio e, não, um fim em si mesma. Com o final do programa Ciência sem Fronteira (CsF) onde mais de 101.000 bolsas de estudo no exterior foram concedidas, projeto de colaboração e programas no exterior têm crescido, estudantes estrangeiros têm vindo estudar no país, assim como professo- 
res e pesquisadores brasileiros têm ido no exterior para estudar e discutir resultados com parceiros estrangeiros.

Os documentos e os atores inseridos na realidade brasileira compartilham do sentido de internacionalização exposto nas discussões dos organismos internacionais e formalizados em seus documentos. A primeira compreensão é situar a internacionalização como a nova missão da universidade na sociedade globalizada. Nesse sentido, a apresentação da internacionalização nos documentos nacionais e internacionais carrega um ideal de cooperação e diplomacia que guarda em seu íntimo a consolidação dos princípios e interesses da sociedade globalizada. Em segundo lugar, os conceitos de competitividade e concorrência estão presentes nos documentos. Santos e Almeida Filho (2012, p. 53) compreendem a necessidade de colocar o saber a serviço da produção de riqueza, ou seja, da criação de condições proporcionadoras de bem-estar individual e coletivo. Sendo assim, a internacionalização torna-se peça da engrenagem da economia do saber.

Portanto é notório que a internacionalização é fundamental e necessária, pois garante a transformação da vida dos estudantes, a sustentação e o crescimento da ciência e do conhecimento por meio de intenso intercâmbio, o potencial de construir capacidades sociais e econômicas. Não é um processo que deve ser entendido apenas pelo viés da economia do saber, mas como proposta de cooperação e democratização internacional do conhecimento produzido. $\mathrm{Na}$ próxima seção, apresentaremos o papel e a posição das universidades no campo da internacionalização.

\section{A UNIVERSIDADE E A INTERNACIONALIZAÇÃO: UMA NOVA MISSÃO?}

A universidade é o terceiro ator envolvido na definição das políticas educacionais para a internacionalização. Já destacamos os atores, documentos e organismos nacionais e internacionais, agora pontuaremos a internacionalização no espaço universitário.

As transformações sociais geradas pela globalização, pelo desenvolvimento tecnológico e pela expansão da informação têm colocado a universidade sobre constante questionamento, sobretudo em relação à sua missão no século XXI. Esse mosaico de interesse que vem atacando a universidade brasileira, somado à globalização e à expansão da tecnologia, contribui para uma crise. Para Santos 
(2010), a universidade atravessa três crises, a saber: de hegemonia, legitimidade e institucional.

Há uma crise de hegemonia sempre que uma dada condição social deixa de ser considerada necessária, única e exclusiva. A universidade sofre uma crise de hegemonia na medida em que a sua incapacidade para desempenhar cabalmente funções contraditórias leva os grupos sociais mais atingidos pelo seu défice funcional ou Estado em nome deles a procurar meios alternativos de atingir seus objetivos. A crise de legitimidade se apresenta sempre que uma dada condição social deixa de ser consensualmente aceita. A universidade sofre uma crise de legitimidade na medida em que se torna socialmente visível a falência dos objetivos coletivamente assumidos. [...] Há uma crise institucional sempre que uma dada condição social estável e auto sustentada deixa de poder garantir os pressupostos que assegura sua reprodução. A universidade sofre uma crise institucional na medida em que sua especificidade organizativa é posta em causa e se lhe pretende impor modelos organizativos vigentes noutras instituições tidas por mais eficientes. (SANTOS, 2010, p. 190).

As três crises da universidade apontadas pelo autor refletem a condição da Educação Superior nos últimos vinte anos. A condição hegemônica da universidade como produtora de conhecimento especializado e de alta cultura, que se fortaleceu desde a Idade Média, encontra-se em profunda crise. Na contemporaneidade, as universidades se veem forçadas a estabelecer novas funções e se adaptar às novas demandas de formação de mão de obra qualificada, fornecer conhecimentos instrumentais e favorecer uma formação cultural segundo padrões médios.

Sobre isso, Fávero (2010, p. 89) levanta um conjunto de questionamentos que merecem ser destacados: "Qual o impacto que todas essas crises terão na configuração das funções da universidade no século XXI? Que desafios ela precisa enfrentar? Qual o futuro da universidade? Conseguirá contornar prudentemente a crise de identidade?". São questionamentos que não podem ser negligenciados no cenário de globalização e internacionalização que a universidade está envolvida.

A dinâmica produtiva do mundo do capital apresenta uma questão central para a crise da universidade. A lógica do capital ao flexibilizar e acelerar os processos produtivos também passou a exigir da universidade uma formação de mão de obra rápida e flexível. É por isso que muitas empresas, por considerarem que a formação universitária é lenta, rígida e dissociada dos interesses diretos 
das demandas do mercado, criam seus próprios cursos de formação profissional. A razão neoliberal ancorada nos princípios de concorrência e competitividade se apresenta como norma para todos os países, instituições, setores da ação pública, domínios da vida social, e é a implantação dessa norma que leva à diminuição da demanda por toda parte, sob o pretexto de tornar a oferta mais "competitiva" (DARDOT; LAVAL, 2016, p. 29). A universidade no contexto do modelo produtivo neoliberal se vê forçada a admitir em seus projetos o produtivismo e a concorrência para uma economia do conhecimento.

Essa condição estruturante do Estado contemporâneo coloca as universidades sob uma crise, especialmente porque o conhecimento passou a ser entendido como mercadoria que pode ser encontrada em outras instituições. Nesse sentido, quais os desafios da internacionalização no modelo de produção flexível? Podemos classificar os seguintes: o primeiro desafio é admitir a internacionalização como uma nova missão de fortalecimento do ensino, pesquisa e extensão diante das contradições do modelo de acumulação flexível. Para Santos e Almeida Filho (2012), a internacionalização é a quarta missão da universidade. Não se trata de entender que está para além do ensino, pesquisa e extensão, mas que a internacionalização como cooperação é a condição de enfretamento da crise universitária.

A posição de Santos e Almeida Filho (2012, p. 57) é, pois, a seguinte:

Esta inevitabilidade histórica com a qual as universidades estão hoje confrontadas - a de, seja qual for o caminho ou os estímulos a que respondem, ou qualquer outra possível consideração de natureza política ou ideológica, de origem ou de antiguidade, de localização geográfica ou de opção estratégica, elas se abrirem à cooperação e a colaboração internacionais como quem marca um encontro final com o destino, para o qual, aliás, vêm sendo preparadas ao longo dos séculos -, reforça no século XXI uma característica universitária que vem desde a Idade Média, afirmando-a como uma evolução específica que está a ponto de se transformar, quase mil anos após a fundação das suas pioneiras e mais veneradas concretizações, na quarta missão da universidade.

Os autores apresentam uma compreensão da internacionalização ancorada no princípio de cooperação, aberta e livre. Essa posição, de certa maneira, é contrária aos pressupostos produtivistas do mundo do capital que têm assolado o espaço acadêmico. Mesmo nos documentos oficiais ou extraoficiais que abordam 
a internacionalização, é comum tratá-la, por vezes, como cooperação democrática e, em outras, como processo de produção de conhecimento para o mundo competitivo do mercado.

De acordo com Azevedo (2009, p. 86), a internacionalização acadêmica deve ser da seguinte fórmula:

Não se trata de um simples mecanismo de permeabilização de fronteiras, mas, sim, um complexo processo de integração a um campo social de produção científica mundializado, em que diversos atores sociais travam relações com vista a intercambiar, a cooperar e a partilhar solidariamente (ou, opostamente, a competir) em suas áreas de atuação e em espações de influência.

O segundo desafio é formalizar e institucionalizar por meio das políticas educacionais a internacionalização como redes solidárias de conhecimentos. Os pesquisadores Chaves e Castro (2016, p. 122), ao dialogarem com Azevedo (2009), ponderam que o autor defende a ideia de que é possível a institucionalização de uma "internacionalização solidária" entre países com respeito ao conhecimento local e à aceitação do "desenvolvimento sustentável", desde que as universidades "conquistem definitivamente a autonomia, tenham qualidade, sejam inclusivas, solidárias e pertinentes socialmente".

Pode-se afirmar que essa perspectiva além de condicionar a existência da conquista da autonomia ignora a organização econômica da sociedade capitalista e o contexto atual de mundialização do capital financeiro que implica na necessidade de uma concorrência acirrada entre os países com vistas a aumentar a competividade econômica. (CHAVES; CASTRO, 2016, p. 123).

O terceiro desafio consiste em formular um Projeto de Desenvolvimento Institucional (PDI) que garanta que a internacionalização seja tratada como forma de internacionalizar regionalizando. A autonomia universitária permite que sejam elaboradas metas e estratégias de internacionalização nos PDIs que rompam com a lógica da mercantilização e favoreçam a missão universitária de compromisso com o local.

Declarar a internacionalização como prioridade institucional requer poder de colocar uma série de ajustes e reformas que querem as práticas internacionais, tais como a integração da internacionalização nos planos e sistemas regulares de planejamento. A elaboração de planos operativos de internacionalização apegados às prioridades institucionais, com definição 
de recursos financeiros e humanos necessários para assegurar a viabilidade. (GACEL-ÁVILA; RODRIGUEZ-RODRIGUEZ, 2018, p. 125).

No contexto das sociedades do conhecimento, a internacionalização como proposta universitária para o século XXI precisa ser amplamente discutida pelas universidades. A elaboração dos PDIs universitários ${ }^{3}$ deve contar com o sentido da internacionalização. O corte dado à internacionalização nesse documento institucional pode fazer dela uma afirmação da missão da universidade com a localidade, estabelecendo como pressuposto uma internacionalização de cooperação, de redes de pesquisadores e alicerçada na promoção dos valores democráticos e de justiça social. Por outro lado, a adoção de um sentido de universalização predatória, vinculada a interesses econômicos, à concorrência e ao produtivismo, tende a enfraquecer a missão da universidade com a justiça social e a democracia. Portanto a internacionalização, dentro das suas várias facetas, com seus diferentes atores e interesses, permite que as universidades, na sua condição de autonomia, elaborem metas e objetivos de internacionalizações adequados aos interesses da instituição e de acordo com os compromissos assumidos com a sua localidade.

O quarto desafio requer o entendimento da mobilidade acadêmica. Como evidenciado por Santos e Almeida Filho (2012), a mobilidade acadêmica é um poderosíssimo parceiro da globalização e decorre da vontade que os sujeitos sentem de complementar sua formação, não apenas nos planos técnicos e científicos, mas igualmente nos aspectos linguísticos, culturais e civilizacionais. Ainda segundo os autores, essas experiências os tornam cidadãos melhores do mundo e, por isso, o Estado e as universidades devem se esforçar para elaborar planos de mobilidade acadêmica que garantam redes de pesquisa, ensino e extensão. Essa

\footnotetext{
${ }^{3}$ Sobre este aspecto, Trevisol e Fávero (2019, p. 1-22) fazem um interessante trabalho de síntese no artigo As diversas faces da internacionalização: análise comparativa entre duas instituições comunitárias do sul do Brasil. Os autores mostram que a internacionalização da Educação Superior tem sido uma das grandes preocupações das universidades, de certas políticas dos principais organismos internacionais (OCDE, Banco Mundial, Unesco) e das agências nacionais de fomento (Capes, CNPq). No entanto os autores destacam que "para além de pressupor a interculturalidade, a integração das pesquisas e dos conhecimentos, a solidariedade entre os povos", a internacionalização "também se caracteriza como sendo um espaço de debates e embates entre os autores do próprio campo e na intercessão dos campos sociais envolvidos". No artigo, os autores analisam "o sentido da internacionalização contido nos documentos de duas universidades comunitárias do Sul do Brasil", ressaltando a necessidade de um olhar crítico sobre este processo.
} 
é uma alternativa de enfrentamento ao modelo de globalização mercantilista e neoliberal que tem atacado as universidades.

Superar esses desafios não é uma tarefa fácil. No modelo de acumulação flexível, o Estado é reformulado e adere a políticas globais. No entender de Harvey (2016), o Estado na acumulação flexível ou no processo de globalização é reformulado e, ao adotar as políticas de privatização, torna-se um empreendedor.

Inegavelmente essa condição, nos dizeres de Akkari (2011, p. 24), nos leva a pensar que "uma das questões mais relevantes em relação às consequências da globalização sobre a educação é se o poder do Estado é enfraquecido pela globalização". Para atender a essa lógica, os Estados são obrigados a favorecer a competitividade econômica global em detrimento da coesão e de projetos sociais internos. A realidade posta evidencia o enfraquecimento do Estado enquanto ente que garante a equidade social. Em outras palavras, o esvaziamento do Estado permite que a lógica global mercantilizada defina os rumos da pesquisa e das políticas educacionais.

O que está em jogo é a diminuição da capacidade do Estado de propor um modelo de desenvolvimento social autônomo e que garanta as particularidades regionais. A pesquisadora Almeida (2010) nos empresta investigações que esclarecem essa dificuldade. Nas palavras da autora, a globalização "sucumbe localidades, nacionalidades, nações e religiões, compreendendo ilhas, arquipélagos e continentes, mares e oceanos; constituindo territorialidades e temporalidades desconhecidas" (ALMEIDA, 2010, p. 40). Nesse sentido, os Estados que não consolidarem projetos articulados com os interesses do povo tendem a se submeter às forças do mercado mundial, que não respeita as identidades, a cultura e os interesses nacionais.

A adoção de um projeto global de desenvolvimento ancorado sobre a lógica neoliberal do mercado mundial poderá trazer situações negativas. Entre elas destacamos, a partir de Akkari (2011), o aumento da desigualdade tecnológica e o distanciamento entre países desenvolvidos e os países menos desenvolvidos, que impedem a igualdade de oportunidades para a partilha mundial equitativa de ciência e tecnologia; criação de um espaço seletivo partilhado por poucos países desenvolvidos, que tendem a dominar os demais países por meio da política e da economia; e a promoção de culturas e valores dominantes de alguns países desenvolvidos e a aceleração do transplante cultural das regiões desenvolvidas para 
as regiões menos desenvolvidas. Para enfrentar essa dimensão da globalização mercantilista, Almeida (2010, p. 40) pondera que "cabe ao estado-nação definir interesses conforme uma população, um território, uma cultura, uma tradição mantendo uma abertura para o estrangeiro e uma identidade nacional".

As colocações da autora abrem um vasto leque para entender e decifrar o Estado Brasileiro diante das políticas de globalização. No entanto vamos nos ater aos desafios das políticas de internacionalização no modelo de acumulação flexível, em outras palavras, como internacionalizar regionalizando e garantindo a identidade regional das instituições de Ensino Superior. Dentro dessa dimensão, podemos pontuar três desafios para o Estado Brasileiro garantir políticas de internacionalização que assegurem um projeto genuíno de nação.

O primeiro desafio é consolidar um projeto educacional que garanta os interesses da população. Não significa uma ruptura com o global e as políticas internacionais para a educação, mas definir quais elementos internacionais ajudam a consolidar um projeto educacional. Para Akkari (2011), as concepções de políticas educacionais, a avaliação dos sistemas educacionais e os financiamentos propostos pelos organismos internacionais (OCDE, Unesco, Banco Mundial etc.) são políticas globais que influenciam e retiram dos Estados (sobretudo os emergentes) a capacidade de consolidar um projeto educacional que assegure os interesses do povo.

O segundo desafio para o Estado Brasileiro é institucionalizar políticas educacionais que garantam a justiça social e a distribuição equitativa. É importante salientar os avanços com a elaboração do Plano Nacional de Educação (2014-2024) e de programas como Prouni ou Ciência sem Fronteiras (CeF). São iniciativas do Estado Brasileiro que exemplificam a possibilidade de concretizar e garantir um projeto nacional de educação. No aspecto da internacionalização, Santos e Almeida Filho (2012) salientam que algumas universidades brasileiras nascem com uma vocação para a internacionalização. Os exemplos são as estratégias de integração regional e a criação de espaços geopolíticos interestaduais ou internacionais. São exemplos desse processo: o Mercosul, no caso da UNILA; a Comunidade dos Países de Língua Portuguesa (CPLP), no caso da UNILAB; a Mesorregião Fronteira Mercosul, no caso da UFFS; e a grande região da Amazônia, no caso da UNIAM.

Por fim, o terceiro desafio para o Estado Brasileiro é garantir fonte de financiamento para as políticas de internacionalização. É a fonte de financiamento 
que garante a mobilidade acadêmica. Um bom exemplo foi o programa Ciência sem Fronteiras. Stallivieri (2017, p. 99) destaca que "em 2010, o governo brasileiro lança o programa Ciência sem Fronteiras, que prevê a destinação de 101 mil bolsas de estudos destinadas a estudantes de graduação, de pós-graduação e pesquisadores". São iniciativas como essa que garantem a internacionalização como um projeto democrático, aberto e solidário de pesquisa e produção de conhecimento.

\section{CONCLUSÃO}

A abordagem sobre os atores, documentos e organismos internacionais e nacionais que tratam da internacionalização do Ensino Superior nos permite apontar algumas conclusões, a saber, em primeiro lugar, que os discursos sobre internacionalização são colonizados por uma lógica empresarial da concorrência e da competitividade, que reduz o papel e a missão da universidade.

Em segundo lugar, a adoção dos conceitos de internacionalização a partir da lógica hegemônica do capital coloca em ameaça os ideais democráticos da ciência como cooperação, solidariedade e justiça social. Estrutura-se, a partir da lógica da economia do saber, uma forma de internacionalização verticalizada e baseada no controle e domínio. Na geopolítica do conhecimento, os países desenvolvidos são os procurados e praticam uma internacionalização ativa, enquanto os países emergentes praticam um tipo de internacionalização da ciência passiva e periférica.

Em terceiro lugar, os atores e documentos internacionais, como OCDE e Unesco, têm influenciado diretamente as políticas de internacionalização adotadas pelo Estado Brasileiro. Observa-se, ainda, que os organismos internacionais, por meio de Declarações e Documentos orientadores, têm exercido um papel importante na disseminação dessas políticas de internacionalização para o campo da Educação Superior, principalmente nos países em desenvolvimento, apresentando a internacionalização como uma condição imprescindível de inserção no mundo globalizado. Os ideais expressos nesses atores e documentos evidenciam um tipo de internacionalização predatória que valoriza os rankings internacionais de publicação e visibilidade da ciência.

Em quarto lugar, a internacionalização como consolidação da lógica da mercantilização aproxima a universidade da empresa. Essa aproximação e, por 
consequência, a adoção de uma racionalidade empresarial baseada na eficiência, flexibilidade, competividade e concorrência, esvazia o sentido do Ensino Superior. Os atores, ao adotarem tal tipo de discurso como meta para as universidades, contribuem para o fortalecimento de sua crise de legitimidade da universidade, pois apontam que outros espaços são mais eficazes na produção de mão de obra preparada para a dinâmica do mercado global.

Em quinto lugar, as universidades, ao adotarem um espírito de autonomia, devem, a partir dos documentos oficiais que tratam da educação no Brasil, construírem espaços de internacionalização alicerçados nos princípios de solidariedade, justiça social e redes de conhecimento.

Portanto a internacionalização do Ensino Superior é fundamental na sociedade globalizada, porém, do ponto de vista social e político, é importante que as universidades tenham clareza sobre qual o tipo de internacionalização que pretendem. O sentido da internacionalização deve estar presente nos Programas de Desenvolvimento Institucional (PDIs) e alinhado com a missão da universidade. Nas questões sobre a política de internacionalização, ainda há muito que fazer e pesquisar.

\section{REFERÊNCIAS}

AKKARI, Abdeljalil. Internacionalização das políticas educacionais: transformações e desafios. Petrópolis, RJ: Vozes, 2011.

ALMEIDA, Maria de Lourdes Pinto de; FÁVERO, Altair Alberto; TONIETO, Carina. A expansão da educação superior no Brasil sob a influência da declaração de Bolonha. In: CATANI, Afrânio Mendes (Org.). O Espaço Europeu de Educação Superior (EEES) para além da Europa: apontamentos e discussões sobre o chamado processo de Bolonha e suas influências. Curitiba: CRV, 2015.

ALMEIDA, Maria de Lourdes Pinto de. A desconstrução da identidade da universidade pública neste início de século XXI: as políticas educacionais neoliberais e a pesquisa científica em xeque. In: ALMEIDA, Maria de Lourdes Pinto de; MENDES, Vitor H. (Org.). (Des)construção da universidade na era do "pós": tensões, desafios e alternativas. Campinas, SP: Mercado de Letras, 2010.

AZEVEDO, Mário Luís Neves de. Integração Regional e Educação Superior: regulações e crises no Mercosul. In: FERREIRA, Eliza Bartolozzi; OLIVEIRA, Dalila Andrade (Org.). Crise da escola e políticas educativas. Belo Horizonte: Autêntica, 2009. v. 1, p. 183-204. 
BAUMAN, Zygmunt. Modernidade líquida. Rio de Janeiro: Zahar, 2001.

BECK, Ulrich. Sociedade de risco: rumo a uma outra modernidade. 2. ed. São Paulo: Editora 34, 2011.

BRASIL. Plano Nacional de Educação (2014-2024). Brasília, DF: Câmara dos Deputados, 2014.

BRASIL. Decreto n. 7.642, de 13 de dezembro de 2011. Institui o Programa Ciência sem Fronteira. Brasília, 2011. Disponível em: http://www.planalto.gov.br/ccivil_03/_Ato20112014/2011/Decreto/D7642.htm. Acesso em: 3 dez. 2018.

BRASIL. Plano Nacional de Pós-Graduação - PNPG 2011-2020. Brasília, DF: Coordenação de Pessoal de Nível Superior (Capes), 2010. v. 1-2.

CAPES. A internacionalização na Universidade Brasileira: resultados do questionário aplicado pela Capes. [Brasília]: Ministério da Educação/Capes, out. 2017. Disponível em: https://www.capes.gov.br/images/stories/download/diversos/A-internacionalizacao-nasIES-brasileiras.pdf. Acesso em: 10 out. 2018.

CENCI, Ângelo Vitório; MARCON, Telmo. Sociedades complexas e desafios educativos: individualização, socialização e democracia. In: MÜHL, Eldon Henrique; DALBOSCO, Cláudio Almir; $\mathrm{CENCl}$, Ângelo Vitório (Org.). Questões atuais de educação: sociedade complexa, pensamento pós-metafísico, democracia e formação humana. Ijuí, RS: Ed. Unijuí, 2016.

CHAVES, Vera Lúcia Jacob; CASTRO, Alda Maria Duarte. Internacionalização da educação superior no Brasil: programas de indução à mobilidade estudantil. Revista Internacional de Educação Superior, Campinas, SP, v. 2, n. 1, p. 118-37, jan./abr. 2016.

DARDOT, Pierre; LAVAL, Christian. A nova razão do mundo: ensaios sobre a sociedade neoliberal. São Paulo: Boitempo, 2016.

DECLARAÇÃO DE BOLONHA. 1999. Disponível em: http://www.direitoshumanos.usp.br/ index.php/Documentos-n\%C3\%A3o-Inseridos-nas-Delibera\%C3\%A7\%C3\%B5es-da-ONU/ declaracao-de-bolonha-1999.html. Acesso em: mar. 2020.

FÁVERO, Altair Alberto. Políticas educacionais e os desafios da universidade no século XXI. In: ALMEIDA, Maria de Lourdes Pinto de; MENDES, Vitor Hugo (Org.). (Des)construção da universidade na era do "pós": tensões, desafios e alternativas. Campinas, SP: Mercado de Letras, 2010. p. 81-97. 
GACEL-ÀVILA, Jocelyne; RODRIGUEZ-RODRIGUEZ, Scilia. Internacionalización de la educación superior en América Latina y el Caribe: un balance. México: UNESCO-IESALC, 2018.

GIDDENS, Anthony. As consequências da modernidade. São Paulo: Unesp, 1991.

HABERMAS, Juergen. A crise de legitimidade no capitalismo tardio. Rio de Janeiro: Edições Tempo Brasileiro, 2002.

HARVEY, David. Condição pós-moderna: uma pesquisa sobre as origens da mudança cultural. 26. ed. São Paulo: Loyola, 2016.

KNIGHT, Jane. International universities: misunderstandings and emerging models? Journal of Studies in International Education, v. 19, n. 2, p. 107-21, fev. 2015.

KOSIK, Karel. Dialética do concreto. 2. ed. Rio de Janeiro: Paz e Terra, 1976.

MIRANDA, José Alberto Antunes de; STALLIVIERI, Luciane. Para uma política pública de internacionalização para o ensino superior. Avaliação: Revista da Avaliação da Educação Superior (Campinas), Sorocaba, SP, v. 22, n. 3, p. 589-613, nov. 2017.

OECD. Internationalization and trade in higher education: opportunities challenges. 2004. Disponível em: https://www.oecd-ilibrary.org/education/internationalisation-and-tradein-higher-education_9789264015067-en. Acesso em: 27 dez. 2018.

SADER, Emir; GENTILI, Pablo (Org.). Pós-neoliberalismo: as políticas sociais e o Estado democrático. Rio de Janeiro: Paz e Terra, 1995.

SANTOS, Boaventura de Sousa. Pela mão de Alice: o social e o político na pós-modernidade. 13. ed. São Paulo: Cortez, 2010.

SANTOS, Fernando Seabra; ALMEIDA FILHO, Naomar de. A quarta missão da universidade: internacionalização universitária na sociedade do conhecimento. Coimbra: Imprensa da Universidade de Coimbra, 2012.

SILVA, Luciana Leandro da. Políticas de formação de professores(as) universitários(as) em São Paulo e Catalunha: tendências e desafios. Educação e Pesquisa, São Paulo, v. 43, n. 1, p. 113-26, jan./mar. 2017.

STALLIVIERI, Luciana. Internacionalização e intercâmbio: dimensões e perspectivas. Curitiba: Appris, 2017. 
TREVISOL, Marcio Giusti; FÁVERO, Altair Alberto. As diversas faces da internacionalização: análise comparativa entre duas instituições comunitárias do Sul do Brasil. Revista Internacional de Educação Superior, Campinas, SP, v. 5, p. 1-22, 2019. Disponível em: https://periodicos.sbu.unicamp.br/ojs/index.php/riesup/article/view/8653894. Acesso em: 6 out. 2019.

UNESCO. Conferência Mundial sobre Ensino Superior 2009: as novas dinâmicas do Ensino Superior e Pesquisas para a Mudança e o Desenvolvimento Social. Paris: [s.n.], 2009.

UNESCO. Ministério da Educação. Educação superior: reforma, mudança e internacionalização. Anais. Brasília, DF: UNESCO/Brasil: SESU, 2003.

\section{Sobre os autores:}

Altair Alberto Fávero: Pós-doutor (Bolsista Capes) pela Universidad Autónoma del Estado de México (UAEMex). Doutor em Educação pela Universidade Federal do Rio Grande do Sul (UFRGS). Mestre em Filosofia do Conhecimento pela Pontifícia Universidade Católica do Rio Grande do Sul (PUC/RS). Especialista em Epistemologia das Ciências Sociais e graduado em Filosofia pela Universidade de Passo Fundo (UPF). Atua como professor e pesquisador no Curso de Filosofia, no Mestrado e Doutorado em Educação da UPF, onde coordena o projeto de Pesquisa Docência Universitária, Políticas Educacionais e Expansão da Educação Superior: Perspectivas e Desafios (em andamento desde março de 2012). Coordenador do Grupo de Estudos e Pesquisas em Educação Superior (GEPES) da UPF, vinculado ao Programa de Pós-Graduação em Educação da UPF, e ao GIEPES ligado à Unicamp. E-mail: altairfavero@gmail.com, Orcid: http://orcid.org/0000-0002-9187-7283

Marcio Giusti Trevisol: Doutorando em Educação na Universidade de Passo Fundo (UPF). Mestre em Ética e Filosofia Política pela Universidade Federal de Santa Catarina (UFSC). Especialista em Metodologia do Ensino de Filosofia pela UPF. Graduado em Filosofia pelo Centro Universitário Assunção (UNIFAI). Professor da Universidade do Oeste de Santa Catarina (Unoesc), atuando nas áreas de Filosofia e Sociologia. Desenvolve atividades de extensão universitária com enfoque na formação de professores das redes pública e privada de ensino. Na pesquisa, desenvolve estudos na área da educação e comunicação. Atualmente, é líder do grupo de pesquisa Comunicação, Mídia e Sociedade. Membro e pesquisador do 
Grupo de Estudos e Pesquisa em Educação Superior (GEPES) da UPF. Participa da Rede Ibero-americana de Estudos e Pesquisas em Políticas e Processos de Educação Superior (RIEPPES - Unoesc/Unicamp) e do Grupo de Estudos e Pesquisas em Políticas de Educação Superior da Região Sul (GEPPES SUL), ambos sediados na PPGEd da Unoesc. E-mail: marcio.trevisol@unoesc.edu.br, Orcid: http://orcid.org/0000-0001-6127-1750

Recebido em 9 de outubro de 2019.

Aprovado em 14 de fevereiro de 2020. 